1

2

3

$4 \quad$ Priya Vizzini ${ }^{\mathrm{a}, \mathrm{b}}$, Marisa Manzano $^{\mathrm{b}}$, Carole Farre $^{\mathrm{c}}$, Thierry Meylheuc ${ }^{\mathrm{a}}$, Carole Chaix ${ }^{\mathrm{c}}$, Nalini

$5 \quad \operatorname{Ramarao}^{\mathrm{a},{ }^{*},}$ Jasmina Vidic ${ }^{\mathrm{a}, *}$

$6 \quad{ }^{a}$ Université Paris-Saclay, INRAE, AgroParisTech, Micalis Institute, 78350, Jouy-en-Josas, 7 France.

8 9

\section{Highly Sensitive Detection of Campylobacter spp. in Chicken Meat using a Silica Nanoparticle Enhanced Dot Blot DNA Biosensor}

${ }^{\mathrm{b}}$ Dipartimento di Scienze AgroAlimentari, Ambientali e Animali, Università di Udine, Italy.

${ }^{c}$ Institut des Sciences Analytiques, UMR 5280, CNRS-UCBL, Université de Lyon, Lyon, France.

*Corresponding author:

E-mail address: jasmina.vidic@inrae.fr

Phone: +33134652737

nalini.ramarao@inrae.fr 
Paper-based DNA biosensors are powerful tools in point-of-care diagnostics since they are affordable, portable, user $\square$ friendly, rapid and robust. However, their sensitivity is not always as high as required to enable DNA quantification. To improve the response of standard dot blots, we have applied a new enhancement strategy that increases the sensitivity of assays based on the use of biotinylated silica-nanoparticles (biotin-Si-NPs). After immobilization of a genomic Campylobacter DNA onto a paper membrane, and addition of a biotinylated-DNA detection probe, hybridization was evidenced using streptavidin-conjugated to horseradish peroxidase (HRP) in the presence of luminol and $\mathrm{H}_{2} \mathrm{O}_{2}$. Replacement of the single biotin by the biotin-Si-NPs boosted on average a 30 fold chemiluminescent read-out of the biosensor. Characterization of biotin-Si-NPs onto a paper with immobilized DNA was done using a scanning electron microscope. A limit of detection of $3 \mathrm{pg} / \mu \mathrm{L}$ of DNA, similar to the available qPCR kits, is achieved, but it is cheaper, easier and avoids inhibition of DNA polymerase by molecules from the food matrices. We demonstrated that the new dot blot coupled to biotin-Si-NPs successfully detected Campylobacter from naturally contaminated chicken meat, without needing a PCR step. Hence, such an enhanced dot blot paves the path to the development of a portable and multiplex paper based platform for point-of-care screening of chicken carcasses for Campylobacter. 
$44 \quad$ Graphical abstract

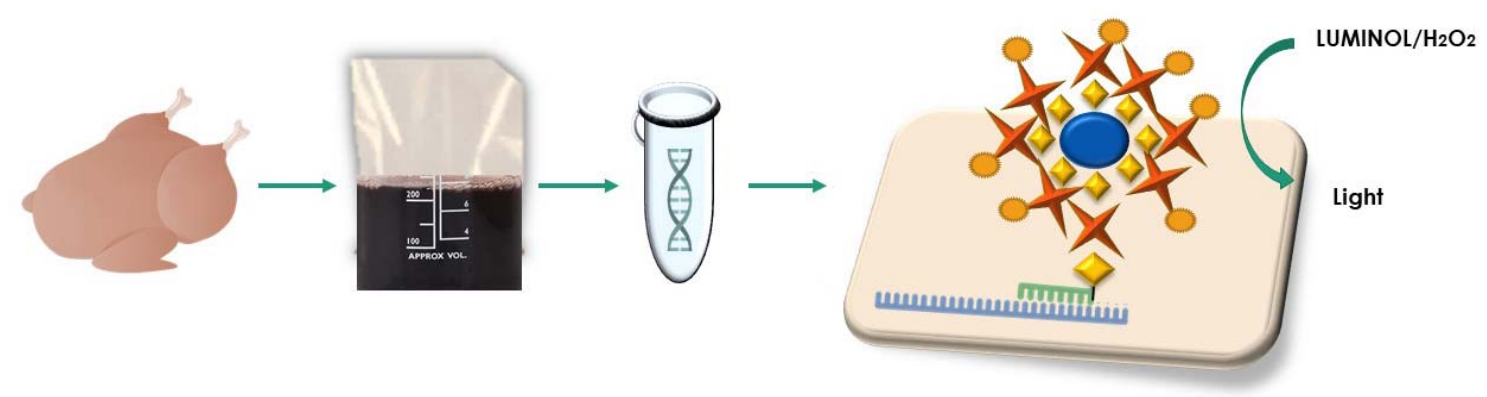

45

46 Keywords: Campylobacter, DNA dot blot, Si-nanoparticles, Food safety, Multiplex

47 bacterial detection. 


\section{Introduction}

Campylobacter is considered the most common bacterial cause of human gastroenteritis in the world. The World Health Organization (WHO) estimates that 550 million people fall ill every year from gastroenteritis, of which 220 million are children (WHO 2020). This zoonosis is transmitted mostly through exposure to under-cooked poultry products (50-80\% cases), and in a minor way, to contaminated milk, vegetables and water (ECDC 2018; Hermans et al. 2012; Humphrey et al. 2007). Campylobacteriosis in humans is usually a self-limiting condition involving bloody diarrhea, abdominal cramping, nausea and fever, which can last up to two weeks. In $1 \%$ of cases, campylobacteriosis evolves to the Guillain-Barré syndrome, a severe autoimmune disease that leads to death in $2-12 \%$ of patients, depending on their age (Scallan Walter et al. 2020). The overall economic burden of campylobacteriosis was estimated to-about EUR 3 billion/year in EU (ECDC 2018), and between US\$ 1.2 and 4 billion/year for the US (Batz et al. 2014). To prevent the entry of Campylobacter contaminated broilers into the market, the European Commission adopted a process hygiene criterion (EU 2017/1495) with the critical limit of $1000 \mathrm{cfu} / \mathrm{g}$ of broiler meat or skin and obligatory systematic screening of broiler carcasses for Campylobacter spp. (EU No 2017/625).

Identification and quantification of Campylobacter spp. rely on official, culture-based methods, and bacterial biochemical/phenotypical characterization (Vizzini et al. 2019). Campylobacter is highly infectious, with reported infective doses as low as 500 cells (Black et al. 1988). To ensure the detection of one cell of Campylobacter in $25 \mathrm{~g}$ of food, an enrichment step in Bolton broth for $24-48 \mathrm{~h}$ is needed, before isolation of the colonies by culturing (it takes about $48-72 \mathrm{~h}$ ) onto selective agar plates incubated in chambers for microaerophilic conditions. Campylobacter is usually present in low numbers in food samples when compared to bacteria like coliforms and Enterobacteriaceae making its isolation on 
common agar media difficult. The official ISO 10272-1:2006 method for Campylobacter detection may provide false negative results because of the possibility Campylobacter death during handling. Furthermore, Campylobacter can enter in a viable but not cultivable (VBNC) status in food matrices, making its detection based on culturing impossible (Vidic et al. 2017; Vizzini et al. 2019). Identification of Campylobacter by the optical microscope is not easy as bacteria can change their spiral distinctive shape into spherical or coccoid. Moreover, the current problem of official methods is the use of a not enough selective medium, and emergence of bacterial resistance against the antibiotic added to the enrichment broth.

Culture-independent molecular methods, such as PCR, and real-time PCR are used as alternatives to colony growth (De Boer et al. 2015; Fontanot et al. 2014; Gosselin-Théberge et al. 2016; Liu et al. 2017; Ricke et al. 2019). However, PCR-based methods may also provide false-negative responses because of the sensitivity of DNA polymerase to inhibitors present in food matrices and enrichment broths (Schrader et al. 2012; Vidic et al. 2019). Next generation sequencing (NGS) which enables sequencing of the entire bacterial genome in a relatively short time has started to be used as a tool for the identification of infectious bacteria. However, NGS can hardly be routinely used at farms and slaughterhouse because it requires special equipment and highly trained personnel for data interpretation (Gosiewski et al. 2017).

Biosensors for detection of Campylobacter show marked advantages over traditional methods in terms of rapidity, facility utilization and cost-effectiveness (Manzano et al. 2015; Masdor et al. 2016; Morant-Miñana and Elizalde 2015; Vidic et al. 2017; Vidic et al. 2019; Vizzini et al. 2019; Yang et al. 2013). However, today no commercial biosensor is available to detect Campylobacter in food matrices, mainly due to the difficulty of attaining a high sensitivity.

Due to significant improvement in biosensor technology over the last two decades, applications of paper-based sensors in pathogen detection are increasing. Such devices seem 
to meet ASSURED criteria (Affordable, Sensitive, Specific, User $\square$ friendly, Rapid and robust, Equipment free and Deliverable) recommended by the WHO for point-of-care diagnostics. Paper as a substrate has the advantage of being inexpensive, lightweight, and easily enables multiplex analysis (Dincer et al. 2019). Various paper-based methods to detect foodborne pathogens have been reported including enzymatic-, immuno- and DNA/RNA- tests (Jokerst et al. 2012; Morales-Narváez et al. 2015; Russell et al. 2017). Tests that target nucleic acids are among the most accurate and specific although they are usually associated with a PCR step, including isothermal amplification, to allow for detection of pathogens in low titers (Trinh et al. 2020; Vidic et al. 2019).

Here, we coupled functionalized silica nanoparticles (Si-NPs) to a paper based DNA dot blot test to enable sensitive Campylobacter nucleic acid detection without a preamplification step. A highly specific DNA probe that recognizes the 16S rRNA gene of the most prevalent Campylobacter spp. causing infections (C. jejuni, C. coli, C. lari, and C. upsaliensis) was used in the test. Si-NPs decorated with biotin (biotin-Si-NPs) were employed to enhance the strepatavidin-HRP chemiluminescent signal read-out. Our study illustrates the proof-of-concept that the collective effect of biotin-Si-NPs could become an effective means for increasing the sensitivity of the cost-effective, specific and easy-to-perform dot blot assay.

\section{Material and Methods}

\subsection{Materials and reagents}

Streptavine-HRP, Proclin, acetonitrile, 1,8-Diazabicyclo[5.4.0]undéc-7-ène (DBU), Controlled pore glass (120-200 Mesh, CPG-3000 Å) were purchased from Sigma-Aldrich (Saint Quentin Fallavier, France). Fluorescent rhodamine B silica NPs (Si-NPs, diameter 50 nm) were supplied by Nano-H (Saint Quentin Fallavier, France). DNA phosphoramidite synthons and all DNA-synthesis reagents were purchased from Glen Research (Sterling, Virginia, USA). Phosphate buffered saline (PBS) was purchased from Dominique Dutscher 
123 (Brumath, France). Amersham Hybond-N+ nylon and Amercham Hybon-XL nitrocellulose

124 membaranes were purchased from ThermoFisher (Illkirch, France). Biomerieux (Bagno a Ripoli, Italy). Triton, SDS, NaCl, trizma-base, phenol, chloroform, bacteriological peptone and isoamyl alcohol were purchased from Sigma (Milan, Italy). A 36mer oligonucleotide related to the $16 \mathrm{~S}$ gene encoding for ribosomal Campylobacter RNA of C. jejuni, C. coli, C. lari, and C. upsaliensis (base location: 72-108) was used as a recognition element (probe named CampyP3). It is interesting to note that the probe matches in three points for each Campylobacter genome at 100\%. CampyP3 was labeled at 5' with biotin for chemiluminescent dot blot assay development. The probe was tested in silico by the OligoAnalyzer3.1 (https://eu.idtdna.com/calc/analyzer), the Amplifix software, Fast PCR 6.1 and Blast (https://blast.ncbi.nlm.nih.gov/Blast.cgi). An ssDNA sequence complementary to the CampyP3 probe, of the same length as the probe was named CP3 and used as positive control. Two ssDNA sequences of the same length as the $\mathrm{CP} 3$, but not complementary to CampyP3, were named PR and PE, and used as negative controls to study selectivity of the sensor through their hybridization with the probe. PR was designed by mismatching positions of nucleic acids of the $\mathrm{CP} 3$ sequence, while PE corresponded to the sequence of $E$. coli (accession number 527445.1) (base location: 338-376 for E. coli), which shows some similarities to Campylobacter. These sequences, reported in Table $1 \mathrm{~S}$, were provided by Sigma-Aldrich (Saint Quentin Fallavier, France) as lyophilized powers. All solutions were prepared using Milli-Q water.

\section{$2.2 \quad$ Bacterial strains}

Bacteria used in this study are listed in Table 2S. Campylobacter strains were grown under microaerophilic conditions $\left(5 \% \mathrm{O}_{2}, 10 \% \mathrm{CO}_{2}\right.$ and $80 \% \mathrm{~N}_{2}$, generated with a Sachet Oxoid ${ }^{\mathrm{TM}}$ 
CampyGen ${ }^{\mathrm{TM}} 2.5 \mathrm{~L}$ (Oxoid, Italy) in anaerobic gas jars at $37^{\circ} \mathrm{C}$ for $48 \mathrm{~h}$, on Columbia blood agar plates. Campylobacter isolates, both reference strains and strain isolates from chicken samples, were subjected to Gram straining and optical microscope observations for cell morphology and motility (Brucella broth, Thermofisher, Milan, Italy) after oxidase and catalase tests.

All negative control strains were grown on their specific culture media at optimal extractions.

\subsection{Sample collection, plate count enumeration and selective isolation}

Five chickens were purchased from local supermarkets in Italy. $10 \mathrm{~g}$ of chicken skin was transferred into a filter-sterile stomacher bag with $40 \mathrm{~mL}$ saline-peptone water $(8 \mathrm{~g} / \mathrm{L} \mathrm{NaCl}, 1$ $\mathrm{g} / \mathrm{L}$ bacteriological peptone) and homogenized in a Stomacher (PBI, Milan, Italy) for $90 \mathrm{~s}$. Aliquots of $0.1 \mathrm{~mL}$ were spread for the mesophilic aerobic count on Triptone Soya Agar, and incubated at $30^{\circ} \mathrm{C}$ for $48 \mathrm{~h}$, while $0.1 \mathrm{~mL}$ were spread on Agar Malt tetracycline at $30^{\circ} \mathrm{C}$ for $48 \mathrm{~h}$ to count yeast/molds. Aliquots of $1 \mathrm{~mL}$ were used with the pour plate method for enumeration of Enterobacteriaceae in the VRBG agar $\left(37^{\circ} \mathrm{C}\right.$ for $\left.24 \mathrm{~h}\right)$, and coliforms and $E$. coli in Coli ID medium $\left(37^{\circ} \mathrm{C}\right.$ for $\left.24 \mathrm{~h}\right)$. Campylobacter detection was performed according to the conventional method ISO 10272-1:2006. For selective bacterial isolation, $10 \mu \mathrm{L}$ of the Bolton broth were streaked onto Skirrow agar plates, and mCCDA (modified charcoalcefoperazone-deoxycholade) plates and incubated at $41.5^{\circ} \mathrm{C}$ for $48 \mathrm{~h}$, under microaerophilic conditions. One colony was selected from mCCDA and streaked on two plates of Columbia blood agar. One plate was incubated at $41.5^{\circ} \mathrm{C}$ for $48 \mathrm{~h}$ in aerobic condition and one plate at $17025{ }^{\circ} \mathrm{C}$ for $48 \mathrm{~h}$ in microphilic condition. Growth on Skirrow served as a confirmation to proceed with the identification steps. 


\subsection{DNA extraction from pure cultures and enrichment broths}

DNA was extracted from reference strains and isolates from chicken samples according to

(Manzano et al. 2015). $2 \mathrm{~mL}$ of Bolton enrichment broth was centrifuged at $13,000 \mathrm{~g}$ at $4{ }^{\circ} \mathrm{C}$

for $10 \mathrm{~min}$, and bacterial pellets were washed three times with PBS 1X, and subjected to extraction (Manzano et al. 2015). Extracted DNAs were rehydrated using $50 \mu \mathrm{L}$ of sterile distilled water and treated with RNase enzyme at $37^{\circ} \mathrm{C}$ for $1 \mathrm{~h}$. Finally, DNA was quantified using a Nanodrop ${ }^{\mathrm{TM}}$ 2000C (ThermoFisher Scientific, Milan Italy) spectrophotometer. The concentration of DNA was adjusted to $100 \mathrm{ng} / \mu \mathrm{L}$ using sterile distilled water.

\subsection{Si-NP synthesis, labeling and quantification}

Si-NPs was functionalized by an innovative solid-phase synthesis technology which enables functionalization of nanosized particles with DNA fragments, as reported previously (Bonnet et al. 2018; De Crozals et al. 2012). Briefly, nanoparticle immobilization onto controlled pore glass (CPG) allows a very high functionalization with a modified

oligonucleotidic based linker. The linker (sequence: dT10-PEG2-dT10) was synthetized using an applied Biosystems 394 RNA/DNA synthesizer (Applied Biosystems). After grafting nanoparticles on a CPG support, they were functionalized by automated synthesis using the phosphoramidite chemistry. First, the linker, that allows a better accessibility of the functions of interest, was synthesized. Second, the biotin group was incorporated. We controlled the biotin incorporation to reach a $10 \%$ coupling yield. To do it, diluted solutions of biotin phosphoramidite $(10 \mathrm{mM})$ and tetrazole in acetonitrile $(45 \mathrm{mM})$ were used and the coupling time was reduced to $10 \mathrm{~s}$. The biotin incorporation was monitored at $498 \mathrm{~nm}$ using dimethoxytrityl quantification by an UV-visible spectrophotometer. Third, biotin-Si-NPs were released from CPG by incubating the support in $1 \mathrm{~mL}$ of $0.1 \%(\mathrm{~m} / \mathrm{v})$ DBU in water- 
before recovering. A fresh DBU solution was added to the CPG suspension every hour. The release kinetics was followed by quantifying the NP concentration in each DBU solution with an UV-visible measurement at $560 \mathrm{~nm}$. Released nanoparticles were washed with milli-Q water $(1 \mathrm{x} 4 \mathrm{~mL}$ then $3 \times 2 \mathrm{~mL})$ and concentrated on $30 \mathrm{~K}$ Amicon Ultra filter $(5000 \mathrm{~g}, 10$ min). Finally, the amount of dT10-PEG2-dT10-10\% Biotin strands per NP was estimated using a Varian Cary 100 Bio UV-visible spectrophotometer (Agilent Technologies) and a quartz cuvette of $1 \mathrm{~cm}$ path length.

The amount of strands per NP was estimated using a Varian Cary 100 Bio UV-visible spectrophotometer (Agilent Technologies) and a quartz cuvette of $1 \mathrm{~cm}$ path length. The amount of linker grafted to nanoparticles was quantified by measuring absorbance in water $(200 \mu \mathrm{L})$ at $260 \mathrm{~nm}$ and $560 \mathrm{~nm}$ with a microplate reader (Perkin Elmer). The nanoparticle concentration was estimated as described previously (Bonnet et al. 2018). To fit with this estimation, we approximated a molar extinction coefficient to $163200 \mathrm{M}^{-1} \mathrm{~cm}^{-1}$ that considers the epsilons of the different parts of the sequence corrected by their corresponding coupling yield.

Functionalized NPs were observed under a transmission electron microscopy (TEM) using a Philips CM120 instrument operating at an accelerate voltage of $120 \mathrm{kV}$ (Centre Technologique des microstructures, Lyon). Si-NPs were observed after deposition of $5 \mu \mathrm{L}$ of diluted solution on a formvar-carbon coated copper grid followed by evaporation until dry.

\subsection{Scanning electron microscopy}

Samples were mounted on aluminum stubs (50 mm diameter) with carbon adhesive discs (Agar Scientific, Oxford Instruments SAS, Gomez-la-Ville, France) and visualized by field emission gun scanning electron microscopy (SEM FEG) as secondary and backscattered electrons images $(5 \mathrm{kV})$ under high vacuum conditions with a Hitachi SU5000 instrument 
220 (Milexia, Verrières-le-Buisson, France). Sample preparation and scanning Electron

221 Microscopy analyses were performed at the Microscopy and Imaging Platform MIMA2

222 (INRAE, Jouy-en-Josas, France).

\subsection{Sample immobilization and detection procedure}

Prior to immobilization onto the nylon membrane, extracted DNAs were denatured at $95{ }^{\circ} \mathrm{C}$ for $10 \mathrm{~min}$, put immediately on ice and $1 \mu \mathrm{L}$ spotted on the positively charged nylon membrane (Amersham Hybon ${ }^{\mathrm{TM}}-\mathrm{XL}$, GE Healthcare, France), which was exposed to UV at $254 \mathrm{~nm}$ for $10 \mathrm{~min}$ to fix DNA. The membrane was then soaked in a pre-wormed hybridization buffer $\left(0.5 \mathrm{M} \mathrm{Na}_{2} \mathrm{HPO}_{4}, 0.5 \mathrm{M} \mathrm{NaH}_{2} \mathrm{PO}_{4}, 10 \mathrm{mM}\right.$ EDTA, $1 \%$ SDS, pH 7.5) at $65^{\circ} \mathrm{C}$ for $30 \mathrm{~min}$ under gentle shaking. $4 \mathrm{ng} / \mu \mathrm{L}$ of the denatured biotin labeled CampyP3 probe $(100 \mathrm{ng} / \mu \mathrm{L})$ was added to the hybridization buffer and left overnight at $65^{\circ} \mathrm{C}$ under gentile shaking to allow for hybridization. was transferred in the blocking buffer $(0.1 \%$ Tween, $0.1 \%$ BSA, $0.03 \%$ Proclin, PBS, pH 7.4) at room temperature for $15 \mathrm{~min}$ to saturate the surface. The membrane was finally incubated with the blocking solution containing $0.7 \mu \mathrm{M}$ streptavidin-HRP for $15 \mathrm{~min}$ at room temperature. After washing with $0.1 \%$ SDS, $150 \mathrm{mM} \mathrm{SSC}$ at room temperature for $5 \mathrm{~min}$, the membrane was incubated with $10^{6}$ biotin-Si-NPs/mL, PBS, pH 7.4 under gentile shaking at room temperature, for $30 \mathrm{~min}$. A $0.7 \mu \mathrm{M}$ streptavidin-HRP in blocking solution was added after washing and incubated for 30 min with shaking. The signal was then revealed using the 241 enhanced chemiluminescent substrate for detection HPR (Thermo Scientific, France). The 242 membrane was removed from the solution and observed under a ChemiDoc MP imaging 243 system (Biorad, France). Detection signals were quantified using Image Lab $^{\mathrm{TM}}$ software 
244 (Biorad). The normalized value of a spot intensity was calculated by $\left(\mathrm{PI}_{0}-\mathrm{PI}_{\mathrm{n}}\right) / \mathrm{PI}_{0}$, where $\mathrm{PI}_{0}$ and $\mathrm{PI}_{\mathrm{n}}$ represent the pixel intensity obtained for detection of $0.1 \mathrm{ng} / \mu \mathrm{L} \mathrm{CP} 3$ probe (standard) and the experimental sample, respectively.

\section{$247 \quad$ Results and discussion}

\subsection{Preparation and characterization of biotin-Si-NPs}

Biotin-Si-NPs were prepared by an innovative solid-phase synthesis technology that by silanization to support the oligonucleotide linker synthesis on the NP surfaces, as previously reported (Bonnet et al. 2018; Farre et al. 2010). In the final step, biotin groups were grafted to the linker. TEM observations showed that the NP morphology was stable during synthesis (Fig. 1A). Functionalized biotin-Si-NPs had an average size of $50 \pm 3 \mathrm{~nm}$, as estimated from TEM images (Fig. 1B). The absorbance measurements suggested that about 500 molecules of the linker were attached to each NP, while dimethoxytrityl quantification indicated the biotin-coupling yield of $10 \%$, which quantified biotin to about 50 per NP (Fig. $1 \mathrm{C})$.

A quite narrow size distribution of functionalized NPs was confirmed by DLS measurements. Si-NPs formed monodisperse aqueous solutions of particles with a hydrodynamic diameter $\left(\mathrm{R}_{\mathrm{H}}\right)$ of about $90 \mathrm{~nm}$. Conjugation of biotin with the linker moieties shifted $\mathrm{R}_{\mathrm{H}}$ to about $120 \mathrm{~nm}$ (Fig. 1D). This increase is probably related to the hydration layer around biotin units linked to arms bearing negatively charged groups. Biotin-Si-NP solutions were stable at $4^{\circ} \mathrm{C}$ for at least two months (Supplementary Material, Figs. 1S and 2S). 
nylon membrane by UV irradiation to enable crosslinking of DNA to the positively charged surface. Thereafter, the DNA probe CampyP3 labeled with biotin was allowed to hybridize with the target DNA. Hybridization was detected with a streptavidin-HRP conjugate in combination with a chemiluminogenic substrate luminol in the presence of the activator $\mathrm{H}_{2} \mathrm{O}_{2}$. In enhanced detection, the streptavidin-biotin sandwich enabled attachment of biotin-Si-NPs to the DNA probe, and consequently amplification of the detection signal compared to a single biotin.

\subsection{Optimization of key parameters and analytical performances of the DNA dot blot} sensor

The time and temperature of hybridization of the DNA probe with its target were optimized as they can markedly influence the sensibility and selectivity of a DNA sensor. First, hybridization of DNA was tested at room temperature, $44^{\circ} \mathrm{C}, 55^{\circ} \mathrm{C}$ and $65^{\circ} \mathrm{C}$ using complementary and non-complementary short ssDNA targets. A complementary DNA target sequence $\mathrm{CP} 3$ (positive control) was detected at all temperatures tested, but only at $65^{\circ} \mathrm{C}$ no non-specific binding was obtained with negative controls, a truncated target sequence (PR) and $E$. coli sequence (PE) (Fig. 3A). Second, hybridization was studied using $1 \mathrm{ng} / \mu \mathrm{L} \mathrm{CP3}$ at $65^{\circ} \mathrm{C}$ for different times from $1 \mathrm{~h}$ to overnight. The overnight incubation provided the highest level of hybridization and maximal signal intensity.

Other parameters that may affect hybridization, such as buffer compositions or the paper support were also tested. The optimization criterion was the best signal-to-background ratio. The nylon membrane allowed for better immobilization of DNA compared to nitrocellulose. The effects of formamide (10, 25, 30, 35 and $50 \%)$, DMSO (0 and 10\%) and SDS $(0,1$ and $10 \%)$ in the hybridization buffer were tested since these denaturing agents for double strained DNA may prevent nonspecific hybridization. The optimal hybridization 
buffer contained SDS, and no DMSO or formamide. We determined that addition of $1 \%$ SDS enhanced the intensity of signals obtained and reduced the frequency of unspecific background staining. The effect of SSC concentrations $(0.5 \mathrm{x}, 1 \mathrm{x}$ and $2 \mathrm{x})$ in the washing buffer was also investigated. A 3-step washing procedure with two buffers $(2 x S S C, 0.1 \%$ SDS and $0.5 x S S C, 0.1 \%$ SDS) lead to elimination of the background signal while maintaining high light intensity of specific spots.

Detection of $1 \mathrm{ng} / \mu \mathrm{L}$ CP3 under the optimized conditions using various concentrations of streptavidin-HRP and biotin-Si-NPs allowed selection of $25 \mathrm{ng} / \mu \mathrm{L}$ of streptavidin-HRP and $10^{6}$ nanoparticles/mL for the chemiluminometric reaction. It is worth noting that the chemiluminometric reaction itself does not significantly contribute to background staining as the emission of light arises from the enzymatic reaction without any photonic excitation (Laios et al. 2010).

\subsection{Calibration curve} intensity for different CP3 concentrations, taken from at least three independent dots per concentration. The linear range for the $\mathrm{CP} 3$ target was from $1 \mathrm{ng} / \mu \mathrm{L}$ to $0.1 \mathrm{ng} / \mu \mathrm{L}$ (with correlation $\mathrm{R}^{2}=0.98684$ ), and from $6 \mathrm{pg} / \mu \mathrm{L}$ to $0.1 \mathrm{ng} / \mu \mathrm{L}$ (with correlation $\mathrm{R}^{2}=0.98935$ ), for classical and biotin-Si-NP enhanced dot blot techniques, respectively (Fig. 3B-D). The limit of detection (LOD) of $0.08 \mathrm{ng} / \mu \mathrm{L}$ and $0.003 \mathrm{ng} / \mu \mathrm{L}$ for classical and enhanced dot blot, respectively, were calculated using $3 \mathrm{~s} / \mathrm{m}$ formula, where ' $\mathrm{s}$ ' is the standard deviation of the blank solution and ' $\mathrm{m}$ ' is the slope of the linear calibration graph. Taking into account the molecular weight of the CP3 of 14395.5, the calculated LOD was $5.5 \mathrm{nM}$ and $0.2 \mathrm{nM}$, for 314 classical and enhanced dot blots, respectively. Consequently, biotin-Si-NPs allowed for 
blot. We estimate LOD of about 600 cells considering that one Campylobacter cell contains 2

317 fg of genomic DNA (Pacholewicz et al. 2013). The low LOD obtained suggests that this enhanced dot blot method may be suitable for meat sample testing as the Campylobacter infection dose is around 500 cells (2.5 pg DNA).

The proposed biosensor showed comparable or enhanced performance in relation to recently reported DNA sensors for Campylobacter detection where the detection limit was 0.5 $\mathrm{ng} / \mu \mathrm{L}$ in (Fontanot et al. 2014), $0.37 \mathrm{ng} / \mu \mathrm{L}$ in (Manzano et al. 2015) and $0.09 \mathrm{nM}$ in (MorantMiñana and Elizalde 2015). The biotin-Si-NP enhanced dot blot reproducibility was estimated to $5 \%$ according to the signal obtained for detection of the same concentration of $\mathrm{CP} 3$. Although our time of analysis is not the lowest reported for Campylobacter detection (Table 1), our assay is, as far as we know, the first one for the Campylobacter detection that has a high sensitivity and does not require the specific bacterial morphology or the background matrix. The colorimetric aptasensor was reported to detect spiral Campylobacter cells but not spherical or coccoid ones (Kim et al. 2018); whereas real-time PCR can be inhibited by molecules and ions presented in enrichment broths or meat (Alves et al. 2016).

SEM was applied to examine different detection steps in order to directly visualize biotin-Si-NPs on the surface of the paper carrying hybridized DNA. The nylon surface before DNA immobilization showed a typical membrane structure, including membrane pores (Figs. quantity of ssDNA. Compared to the surface of the bare membrane, the surface of membrane carrying DNA became irregular showing increased morphological heterogeneity. ssDNA molecules seemed to rest horizontally positioned over the surface (Fig. 4, right upper panel). 
340 fibril structures than the ones with only immobilized ssDNA molecules (Fig. 4, lower panel).

341 Biotin-Si-NPs were easily detected on double strain DNA as small beads of about $50 \mathrm{~nm}$ in

342 diameter. It is worth to note, that because the DNA probe matches three points in the

343 Campylobacter genome, several biotin-Si-NPs may specifically bind to one DNA. Overall,

344 SEM images confirmed efficient DNA immobilization and hybridization by revealing that the

345 nylon surface became more complex after each stage of the detection process and that

346 hybridized DNA were decorated with nanoparticles of the expected size of $50 \mathrm{~nm}$.

To examine the selectivity and sensitivity of the biotin-Si-NPs dot blot, we tested various strains of Campylobacter spp. for inclusivity, and 17 other bacterial species and 1 yeast strain for exclusivity (Fig. 5). All strains were cultivated as monocultures and genomic DNA were extracted as explained in the experimental part. Dot blot analyses were performed using $10 \mathrm{ng} / \mu \mathrm{L}$ of non-amplified extracted DNA. Before immobilization, all genomic DNA were denatured for $5 \mathrm{~min}$ at $95^{\circ} \mathrm{C}$ to allow double strain opening. $\mathrm{CP} 3$ at $0.1 \mathrm{ng} / \mu \mathrm{L}$ was used as an internal control to normalize signal intensities. The signal ratios for $C$. jejuni, $C$. coli, $C$. lari, and C. upsaliensis over CP3 were higher than 1.0, with the membrane images exhibiting obvious dots. Moreover, the intensity obtained for $C$. jejuni and $C$. coli were about 4 times higher than that of the positive control. In contrast, the highest ratio among control DNA and CP3 was only 0.6 for $S$. enterica (background staining). The obtained results highlight the specificity of detection. In addition, the CampyP3 detection probe reacted with DNA of $C$. jejuni and C. coli more efficiently than with DNA of other Campylobacter spp. tested. Our results demonstrated that the biotin-Si-NPs enhanced dot blot platform is sensitive enough to 362 detect the whole DNA extracted from the most frequent Campylobacter spp. and could 363 distinguish between Campylobacter and other bacteria. This specificity of the CampyP3 
364 probe suggests that no nonspecific signal will be generated upon testing DNAs of competing 365 total mesophilic flora in chicken meat.

To demonstrate the capabilities of our developed biosensor for possible real-world applications, we have chosen to target the detection of Campylobacter in chicken meat samples. The results of plate count enumeration for background bacteria in five chicken samples are reported in Table 3S. The ISO 10272-1:2006 indicated that two out of five samples were contaminated with Campylobacter (Table 4S). Indeed, only isolates from selective media (mCCDA, Skirrow and Columbia agar) of samples C3 and C10 were confirmed for Campylobacter by the temperature growth and motility test.

In dot blot analysis, the CP3 template $(0.1 \mathrm{ng} / \mu \mathrm{L})$ was used as a positive control. The dot blot enhanced with biotin-Si-NP successfully detected two contaminated samples, C3 and the CampyP3 detection probe. The proposed biotin-Si-NP enhanced dot blot method, thus, specifically detected low levels of naturally present Campylobacter after enrichment and could be considered for determination and detection of Campylobacter spp. in contaminated chicken meat. Compared to the official ISO 11272: 2006 method, the new DNA dot blot biosensor is less laborious, more cost-effective and time-saving. First, the highly selective DNA detection probe enables selective detection of Campylobacter in the presence of meat background bacteria, and thus no culturing on a selective agar is needed. Second, enhancement of the detection signal intensity allows DNA detection without PCR preamplification.

\section{Conclusion}


This work describes the DNA dot blot method enhanced with biotin-Si-NPs for easy, fast and reliable detection of Campylobacter spp. in contaminated chicken meats. The dot blot test is widely used in molecular biology and genetics for detecting target DNA/RNA sequences. This paper-based hybridization can easily analyze multiple samples inexpensively in a high-throughput fashion but has limitation in a low sensitivity. We demonstrated that association of highly functionalized biotin-Si-NPs with the chemiluminescent read-out of the dot blot enhanced the signal about 30 times. Furthermore, biotin-Si-NPs are robust at working temperature and stable in time. The LOD obtained was $3 \mathrm{pg} / \mu \mathrm{L}(0.2 \mathrm{nM})$. Such a low concentration of detected DNA is close to values that can be detected by qPCR (Manzano et al. 2018; Vidic et al. 2019). Hybridization of immobilized genomic DNA with the CampyP3 probe induced positive signals for different Campylobacter spp. responsible for human gastroenteritis, while no background staining was observed with control samples. The developed system is a promising tool for fast and cheap screening of poultry samples for the presence of Campylobacter since detection is performed on bacterial DNA without a preamplification step. Furthermore, our dot blot can be applied on DNA extracted by different extraction methods and from various food matrices, as it is not sensitive to DNA polymerase inhibitors.

The proposed sensitive, miniaturized and multiplex paper-based test is simple to design and could be used by the food industry and regulatory agencies for the detection of 406 other pathogens to monitor food quality. We believe that in the future it could be integrated into a Lab-on-the chip based biosensor that comprises an automatized DNA extraction 408 protocol and a mobile phone camera (Kalligosfyri et al. 2019; Vidic et al. 2019). 
410 A list of oligonucleotides and bacterial strains used in this studies, stability of biotin-Si-

411 nanoparticles, as well as the results obtained by the plate count method on chicken samples 412 are available in the supplementary material associated with this article.

\section{Acknowledgements}

415 The authors thank the Centre Technologique des Microstructures of the Lyon 1 University 416 for providing access to its TEM facilities, and the MIMA2 platform Jouy en Josas for access

417 to electron microscopy equipment (MIMA2, INRAE, 2018. Microscopy and Imaging Facility 418 for Microbes, Animals and Foods, https://doi.org/10.15454/1.5572348210007727E12). JV 419 thanks Maria-Vesna Nikolic (University of Belgrade, Serbia) for English editing. PV 420 acknowledges a doctoral fellowship from the University of Udine, Italy. This research was 421 supported in part by the European Union's Horizon 2020 research and innovation programme 422 under the Marie Skłodowska-Curie grant agreement No 872662 (IPANEMA), the European 423 Union's Horizon 2020 research and by the University Paris-Saclay through the Poc in labs 4242019 grant agreement No 00003469 (OSCAR). 


\section{References}

Alves, J., Hirooka, E.Y., de Oliveira, T.C.R.M., 2016. Development of a multiplex real-time PCR assay with an internal amplification control for the detection of Campylobacter spp. and Salmonella spp. in chicken meat. LWT-Food Science and Technology 72, 175-181.

Batz, M., Hoffmann, S., Morris Jr, J.G., 2014. Disease-outcome trees, EQ-5D scores, and estimated annual losses of quality-adjusted life years (QALYs) for 14 foodborne pathogens in the United States. Foodborne pathogens and disease 11(5), 395-402.

Black, R.E., Levine, M.M., Clements, M.L., Hughes, T.P., Blaser, M.J., 1988. Experimental Campylobacter jejuni infection in humans. Journal of infectious diseases 157(3), 472-479. Bonnet, R., Farre, C., Valera, L., Vossier, L., Léon, F., Dagland, T., Pouzet, A., Jaffrézic-Renault, N., Fareh, J., Fournier-Wirth, C., 2018. Highly labeled methylene blue-ds DNA silica nanoparticles for signal enhancement of immunoassays: application to the sensitive detection of bacteria in human platelet concentrates. Analyst 143(10), 2293-2303.

De Boer, P., Rahaoui, H., Leer, R., Montijn, R., Van der Vossen, J., 2015. Real-time PCR detection of Campylobacter spp.: a comparison to classic culturing and enrichment. Food microbiology 51, 96100.

De Crozals, G., Farre, C., Hantier, G., Léonard, D., Marquette, C.A., Mandon, C.A., Marmuse, L., Louis, C., Toulmé, J.-J., Billotey, C., 2012. Oligonucleotide solid-phase synthesis on fluorescent nanoparticles grafted on controlled pore glass. RSC advances 2(31), 11858-11866.

Dincer, C., Bruch, R., Costa-Rama, E., Fernández-Abedul, M.T., Merkoçi, A., Manz, A., Urban, G.A., Güder, F., 2019. Disposable sensors in diagnostics, food, and environmental monitoring. Advanced Materials 31(30), 1806739.

ECDC, E.a., 2018. The European Union summary report on trends and sources of zoonoses, zoon otic agents and food-borne outbreaks in 2017. EFSa Journal 16(12), e05500.

Farre, C., Lansalot, M., Bazzi, R., Roux, S., Marquette, C.A., Catanante, G., Blum, L.c.J., Charvet, N., Louis, C., Chaix, C., 2010. Automated oligonucleotide solid-phase synthesis on nanosized silica particles using nano-on-micro assembled particle supports. Langmuir 26(7), 4941-4950.

Fontanot, M., lacumin, L., Cecchini, F., Comi, G., Manzano, M., 2014. Rapid detection and differentiation of important Campylobacter spp. in poultry samples by dot blot and PCR. Food microbiology 43, 28-34. Gosiewski, T., Ludwig-Galezowska, A., Huminska, K., Sroka-Oleksiak, A., Radkowski, P., Salamon, D., Wojciechowicz, J., Kus-Slowinska, M., Bulanda, M., Wolkow, P., 2017. Comprehensive detection and identification of bacterial DNA in the blood of patients with sepsis and healthy volunteers using nextgeneration sequencing method-the observation of DNAemia. European Journal of Clinical Microbiology \& Infectious Diseases 36(2), 329-336.

Gosselin-Théberge, M., Taboada, E., Guy, R.A., 2016. Evaluation of real-time PCR assays and standard curve optimisation for enhanced accuracy in quantification of Campylobacter environmental water isolates. Journal of microbiological methods 129, 70-77.

Hermans, D., Pasmans, F., Messens, W., Martel, A., Van Immerseel, F., Rasschaert, G., Heyndrickx, M., Van Deun, K., Haesebrouck, F., 2012. Poultry as a host for the zoonotic pathogen Campylobacter jejuni. Vector-Borne and Zoonotic Diseases 12(2), 89-98.

Humphrey, T., O'Brien, S., Madsen, M., 2007. Campylobacters as zoonotic pathogens: a food production perspective. International journal of food microbiology 117(3), 237-257. Jokerst, J.C., Adkins, J.A., Bisha, B., Mentele, M.M., Goodridge, L.D., Henry, C.S., 2012. Development of a paper-based analytical device for colorimetric detection of select foodborne pathogens. Analytical chemistry 84(6), 2900-2907. 
473 Kalligosfyri, P.M., Sevastou, A., Kyriakou, I.K., Tragoulias, S.S., Kalogianni, D.P., Christopoulos, T.K., 474 2019. Smartphone-based chemiluminometric hybridization assays and quantitative competitive 475 polymerase chain reaction. Analytica Chimica Acta 1088, 123-130.

476 Kim, Y.-J., Kim, H.-S., Chon, J.-W., Kim, D.-H., Hyeon, J.-Y., Seo, K.-H., 2018. New colorimetric 477 aptasensor for rapid on-site detection of Campylobacter jejuni and Campylobacter coli in chicken 478 carcass samples. Analytica chimica acta 1029, 78-85.

479 Laios, E., Ioannou, P.C., Christopoulos, T.K., 2010. Gene Assays Based on Bio (Chemi) luminescence. 480 Chemiluminescence and Bioluminescence, pp. 334-377. RSC Publishing, Cambridge, UK.

481 Liu, K.C., Jinneman, K.C., Neal-McKinney, J., Wu, W.-H., Rice, D.H., 2017. Simultaneous identification

482 of Campylobacter jejuni, Campylobacter coli, and Campylobacter lari with smartcycler-based multiplex quantitative polymerase chain reaction. Foodborne Pathogens and Disease 14(7), 371-378. Manzano, M., Cecchini, F., Fontanot, M., lacumin, L., Comi, G., Melpignano, P., 2015. OLED-based DNA biochip for Campylobacter spp. detection in poultry meat samples. Biosensors and bioelectronics 66, 271-276.

Manzano, M., Viezzi, S., Mazerat, S., Marks, R.S., Vidic, J., 2018. Rapid and label-free electrochemical DNA biosensor for detecting hepatitis A virus. Biosensors and Bioelectronics 100, 89-95.

Masdor, N.A., Altintas, Z., Tothill, I.E., 2016. Sensitive detection of Campylobacter jejuni using nanoparticles enhanced QCM sensor. Biosensors and Bioelectronics 78, 328-336.

Morales-Narváez, E., Golmohammadi, H., Naghdi, T., Yousefi, H., Kostiv, U., Horak, D., Pourreza, N., Merkoçi, A., 2015. Nanopaper as an optical sensing platform. ACS nano 9(7), 7296-7305.

Morant-Miñana, M.C., Elizalde, J., 2015. Microscale electrodes integrated on COP for real sample Campylobacter spp. detection. Biosensors and Bioelectronics 70, 491-497.

Pacholewicz, E., Swart, A., Lipman, L.J., Wagenaar, J.A., Havelaar, A.H., Duim, B., 2013. Propidium monoazide does not fully inhibit the detection of dead Campylobacter on broiler chicken carcasses by qPCR. Journal of microbiological methods 95(1), 32-38.

Ricke, S.C., Feye, K.M., Chaney, W.E., Shi, Z., Pavlidis, H., Yang, Y., 2019. Developments in rapid detection methods for the detection of foodborne Campylobacter in the United States. Frontiers in Microbiology 9, 3280.

Russell, S.M., Doménech-Sánchez, A., de la Rica, R., 2017. Augmented reality for real-time detection and interpretation of colorimetric signals generated by paper-based biosensors. Acs Sensors 2(6), 848-853.

Scallan Walter, E.J., Crim, S.M., Bruce, B.B., Griffin, P.M., 2020. Incidence of Campylobacterassociated Guillain-Barre Syndrome estimated from health insurance data. Foodborne Pathogens and Disease 17(1), 23-28.

Schrader, C., Schielke, A., Ellerbroek, L., Johne, R., 2012. PCR inhibitors-occurrence, properties and removal. Journal of applied microbiology 113(5), 1014-1026.

Trinh, K.T.L., Stabler, R.A., Lee, N.Y., 2020. Fabrication of a foldable all-in-one point-of-care molecular diagnostic microdevice for the facile identification of multiple pathogens. Sensors and Actuators B: Chemical, 128057.

Vidic, J., Manzano, M., Chang, C.-M., Jaffrezic-Renault, N., 2017. Advanced biosensors for detection of pathogens related to livestock and poultry. Veterinary research 48(1), 11.

Vidic, J., Vizzini, P., Manzano, M., Kavanaugh, D., Ramarao, N., Zivkovic, M., Radonic, V., Knezevic, N., Giouroudi, I., Gadjanski, I., 2019. Point-of-need DNA testing for detection of foodborne pathogenic bacteria. Sensors 19(5), 1100.

Vizzini, P., Braidot, M., Vidic, J., Manzano, M., 2019. Electrochemical and optical biosensors for the detection of campylobacter and listeria: An update look. Micromachines 10(8), 500.

WHO, 2020. World Health Organization. Campylobacter. Available online: https://www.who.int/news-room/fact-sheets/detail/campylobacter.

Yang, X., Kirsch, J., Simonian, A., 2013. Campylobacter spp. detection in the 21st century: A review of the recent achievements in biosensor development. Journal of microbiological methods 95(1), 48-56. 
525 Table 1. Analytical parameters of methods for Campylobacter spp. detection.

\begin{tabular}{|c|c|c|c|}
\hline Method & LOD & $\begin{array}{l}\text { Analysis } \\
\text { time }\end{array}$ & Reference \\
\hline $\begin{array}{l}\text { Culture- } \\
\text { based } \\
\text { methods }\end{array}$ & $1 \mathrm{CFU} / 25 \mathrm{~g}$ & $\begin{array}{c}\geq 5 \\
\text { days }\end{array}$ & (Vizzini et al. 2019) \\
\hline $\begin{array}{l}\text { Real-time } \\
\text { PCR }\end{array}$ & $3 \times 10^{3} \mathrm{CFU} / \mathrm{mL}$ & 0.5 to $4 \mathrm{~h}$ & (Alves et al. 2016) \\
\hline Dot blot & $0.37 \mathrm{ng} / \mu \mathrm{L}$ & $24 \mathrm{~h}$ & (Manzano et al. 2015) \\
\hline $\begin{array}{l}\text { Colorimetric } \\
\text { aptasensor }\end{array}$ & $7.2 \square \times \square 10^{5} \square \mathrm{CFU} / \mathrm{mL}$ & $30 \mathrm{~min}$ & (Kim et al. 2018) \\
\hline $\begin{array}{l}\text { Enhanced } \\
\text { dot blot }\end{array}$ & $\begin{array}{l}3 \mathrm{pg} / \mu \mathrm{L} \text { or } \\
600 \mathrm{CFU}\end{array}$ & $24 \mathrm{~h}$ & This work \\
\hline
\end{tabular}




\section{Figure legends:}

528 Figure 1. (A) TEM images of Si-NPs before and after functionalization with linker and 529 biotin. (B) Histogram showing the average particle size $50 \pm 3 \mathrm{~nm}$ before functionalization. 530 (C) Absorbance spectra of Si-NPs (before functionalization) and biotin-Si-NPs (after 531 functionalization). (D) DLS size plots of native and biotin functionalized Si-NPs in water.

Figure 2. Schematic representation of Campylobacter detection based on paper-based DNA 534 hybridization with a complementary biotinylated probe, and a streptavidin-HRP read-out through dot blot (A). The signal was amplified using highly functionalized biotin-Si-NPs instead of a single biotin (B).

Figure 3. (A) Dot blot detection of Campylobacter DNA sequence with biotin-Si-NP enhanced read-out. Note that no signal was obtained with a truncated Campylobacter

540 sequence (PR) nor with an E. coli control sequence (PE). (B) Conventional dot blot detection of biotin labeled CampyP3 probe using dilution of complementary Campylobacter sequence

$542 \mathrm{CP} 3$ ranging from $1 \mathrm{ng} / \mu \mathrm{L}$ to $78 \mathrm{fg} / \mu \mathrm{L}$. (C) Enhanced dot blot detection of $\mathrm{CP} 3(0.1 \mathrm{ng} / \mu \mathrm{L}-$ plotting the chemiluminescent signal intensity of dots as a function of CP3 template concentrations.

547 Figure 4. SEM images of the basic nylon membrane, nylon membrane functionalized with a C. jejuni DNA, and nylon membrane with CampyP3 hybridized with $C$. jejuni DNA and with biotin-Si-NPs. Note that the size of visualized circular beads of about $50 \mathrm{~nm}$ (yellow shading) corresponded to the estimated NP size in Fig 1B. 
552 Figure 5. Inclusivity and exclusivity test results of the enhanced dot blot biosensor in pure

553 bacterial cultures. Signal intensity were normalized using an intern control (CP3 template).

554 Error bars represent the standard deviation of the mean from triplicates.

555

556 Figure 6. Schematic diagram of Campylobacter detection from chicken samples using the 557 enhanced dot blot and the official ISO 10272-1:2006 method. The ISO method involved steps 558 performed to obtain the results given in Table 4. Dot blot membrane shows representative dot 559 blot results obtained with naturally infected chicken samples (C3 and C10) and non-infected 560 chicken samples (C4, C5 and C6). CP3 template sequence $(0.1 \mathrm{ng} / \mu \mathrm{L})$ was used as a positive 561 control. 
$A$

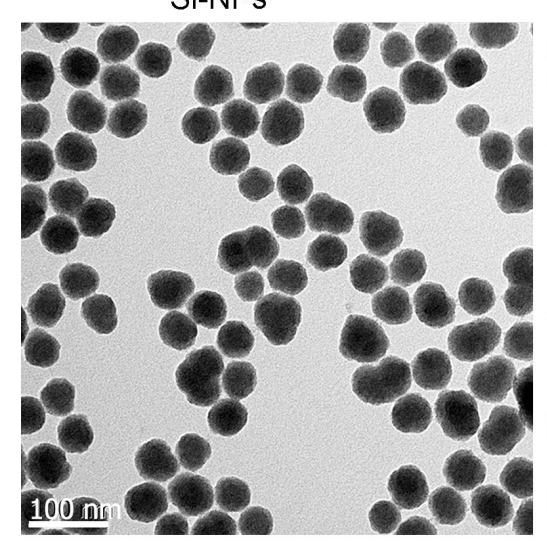

Linker-Si-NPs

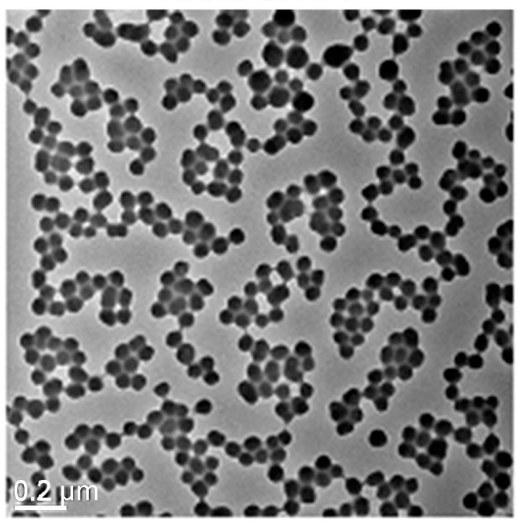

Biotin-Si-NPs

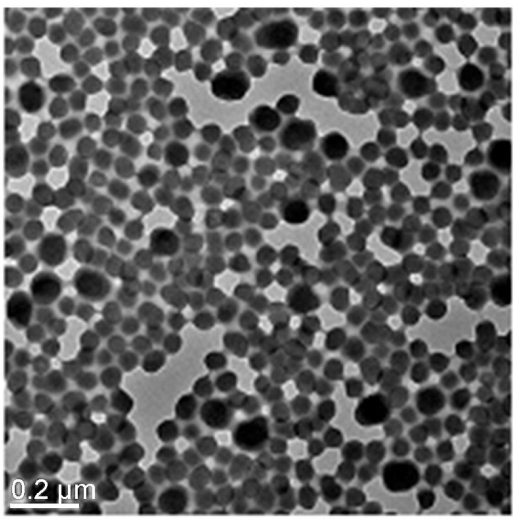

D
B

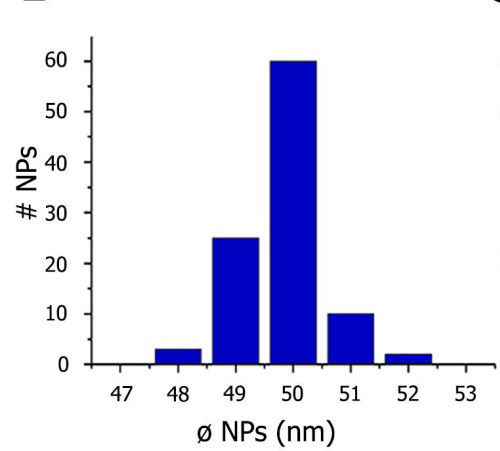

C

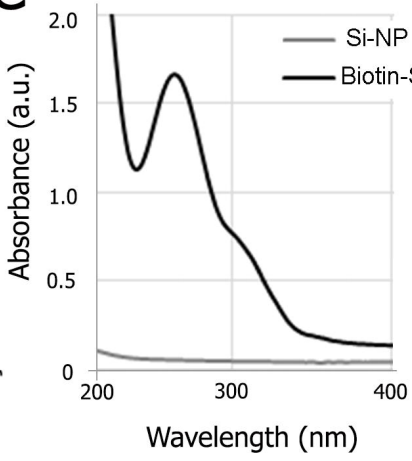

Si-NP

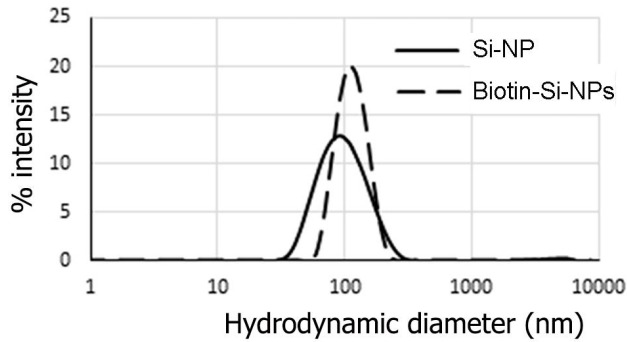


A
B

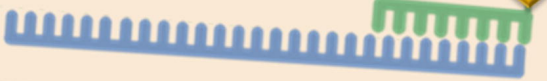

Luminol / $\mathrm{H}_{2} \mathrm{O}_{2}$

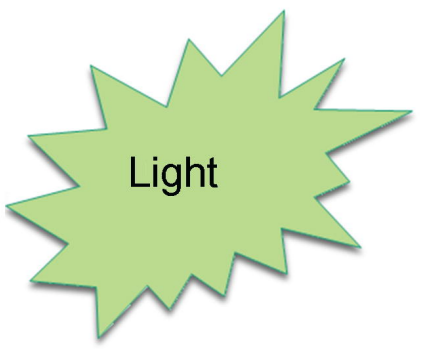

Streptavidine

HRP

unm DNA probe

Si-NP

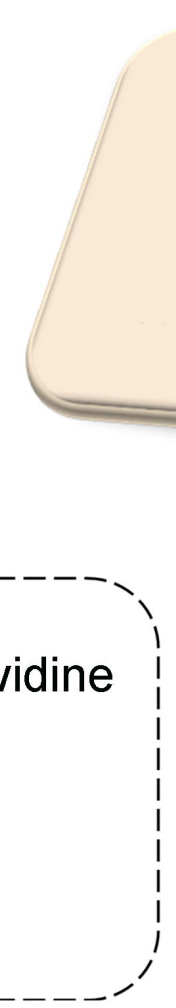

Luminol / $\mathrm{H}_{2} \mathrm{O}_{2}$
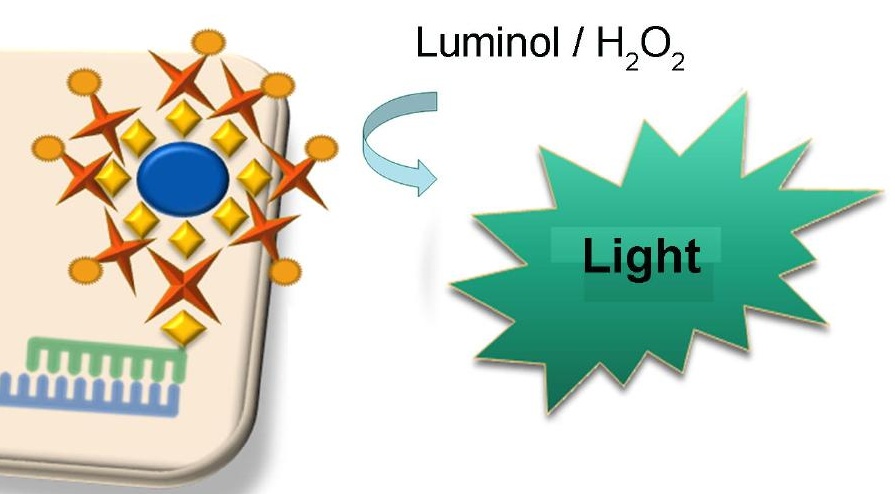
A

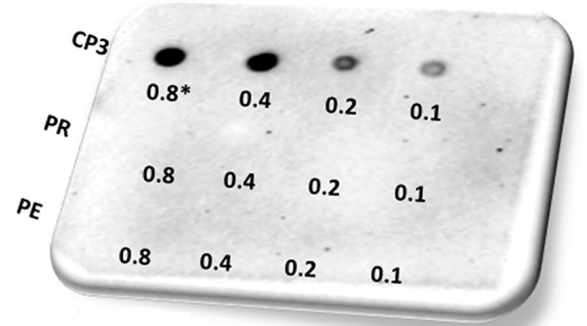

B

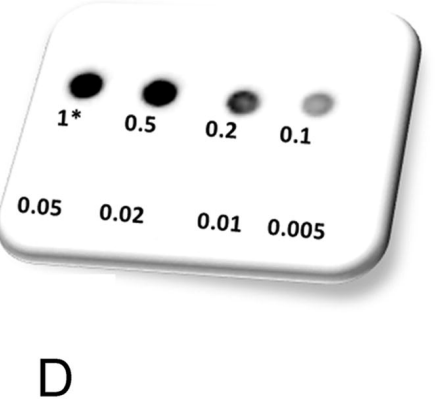

Without NPs

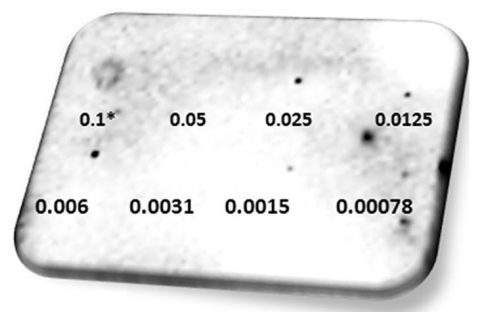

C

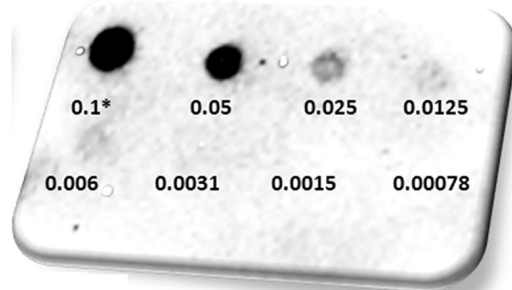

E
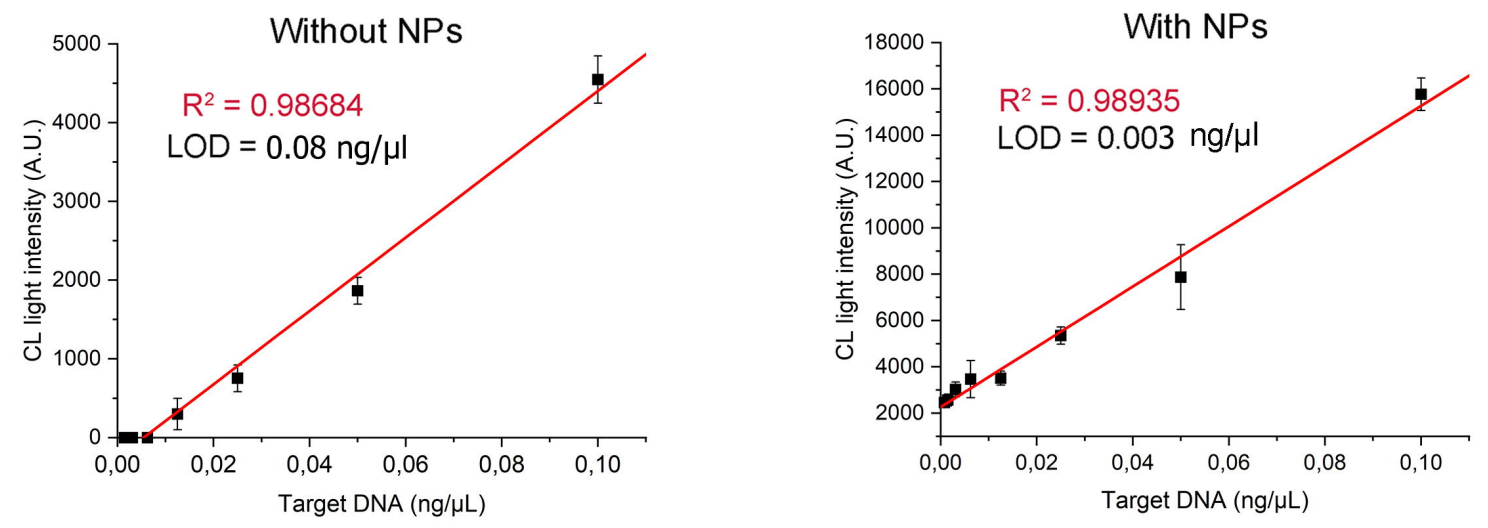

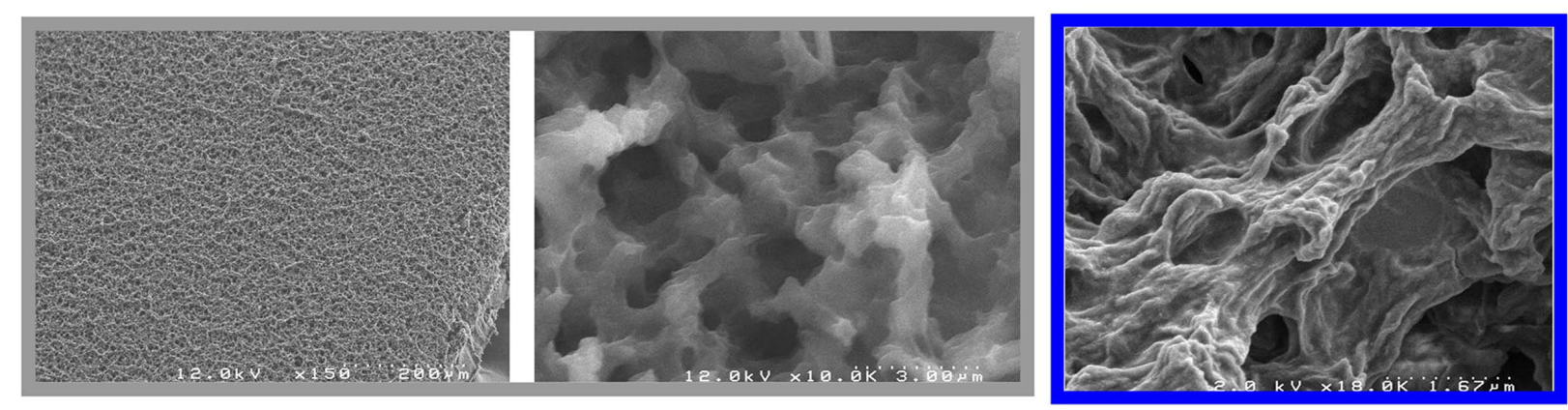

Biotin-Si-NPs-DNA-DNA

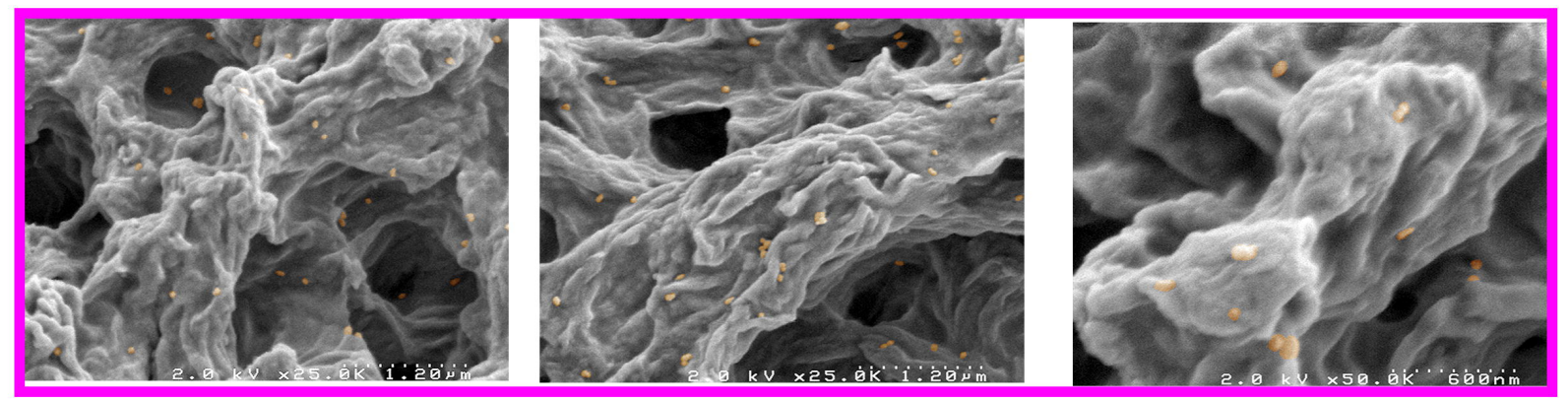




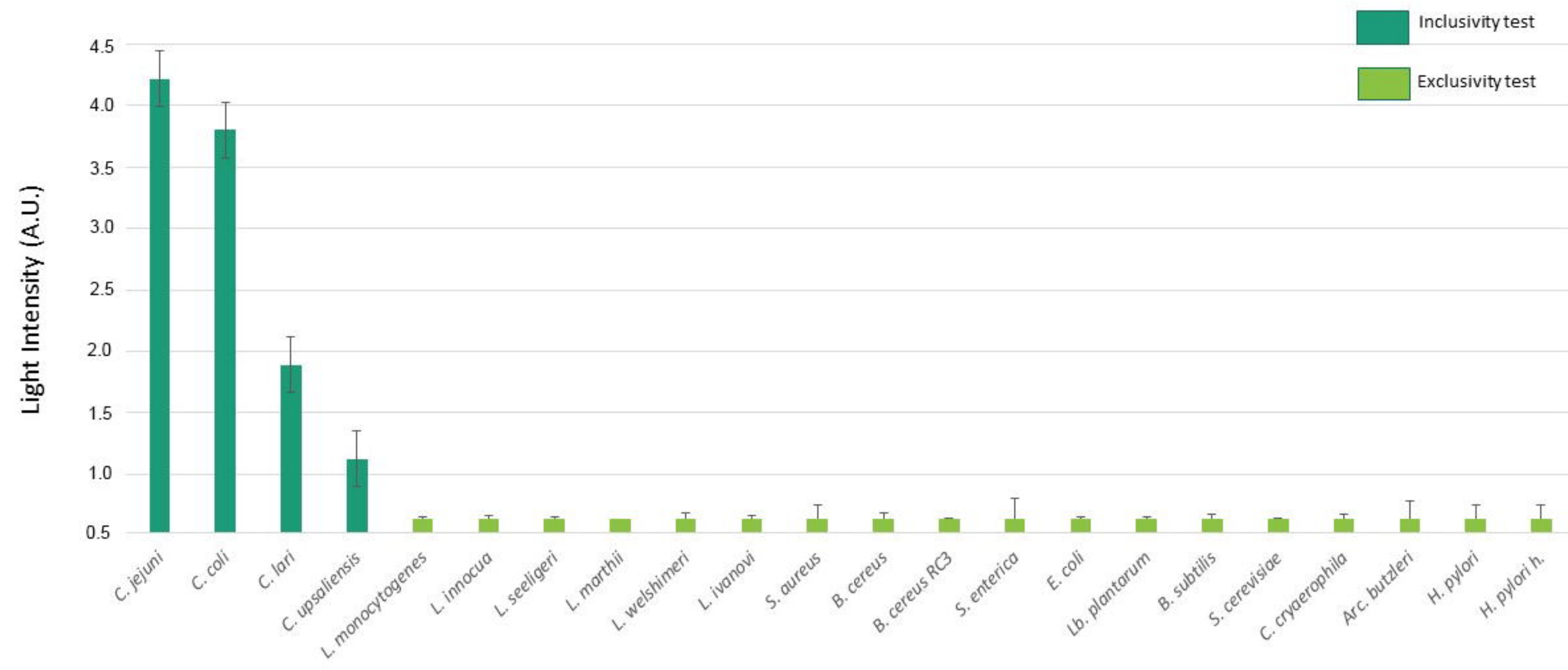


$10 \mathrm{~g}$ of chicken meat

$+$

$90 \mathrm{~mL}$ Bolton broth

$48 \mathrm{~h}$ incubation

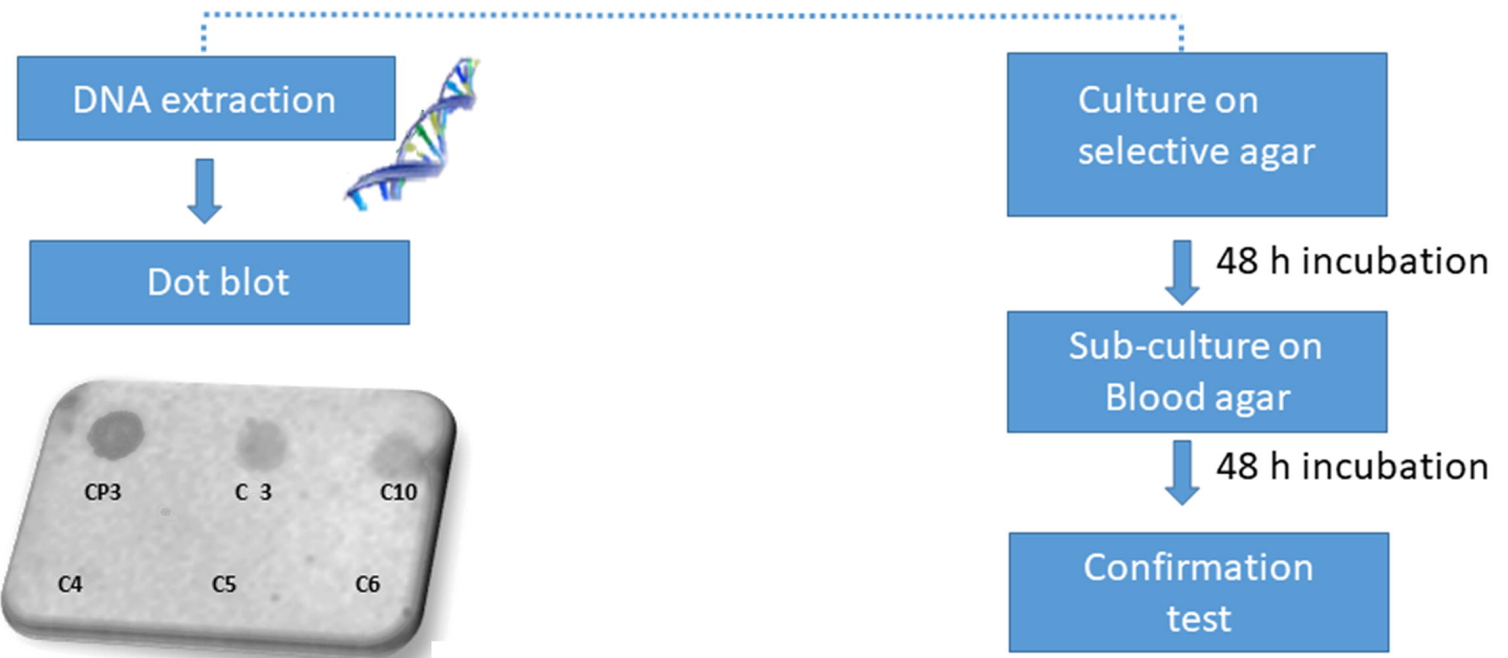

